\title{
How do unfamiliar environments convey meaning to older people? Urban dimensions of placelessness and attachment
}

\author{
By Judith Phillips ${ }^{1}$, Nigel Walford ${ }^{2} \mathcal{E}$ AnN \\ HOCKEY ${ }^{3}$
}

\begin{abstract}
The discussion within gerontology of the relationship between older people and their environment (place attachment and ageing in place in particular) has been based on an assumption of familiarity with place. Yet increasingly older people experience unfamiliar environments. This can be through increased travelling as tourists and visitors to other towns and cities, through redevelopment of town centres or through cognitive decline, where the familiar becomes unfamiliar. This article reviews the conceptual frameworks underpinning the concepts of place attachment and unfamiliarity and questions the relevance of such concepts for understanding urban lifestyles in later life. We demonstrate that even in an unfamiliar environment older people can develop a sense of place through the aesthetics and usability of the environment as well as through

${ }^{1}$ Judith Phillips, Centre for Innovative Ageing, Swansea University, Swansea, UK

${ }^{2}$ Nigel Walford, Centre for Earth and Environmental Sciences Research, Kingston University, Kingston, UK

${ }^{3}$ Ann Hockey, Built Environment Research Group, Anglia Ruskin University, Chelmsford, UK
\end{abstract}


International Journal of Ageing and Later Life

shared memories. Consequently this has relevance for how we plan our environments to make them age-friendly.

Keywords: ageing, unfamiliar environments, attachment to place, sense of place, placelessness.

\section{Introduction}

Studies of the ways in which place conditions and contributes meaning to everyday life have tended to focus on people's relationship with familiar spaces. This is particularly relevant in studies of older people's attachment to place where meaning and a sense of place have developed through a lifetime of memories and associations. Increasingly older people experience unfamiliar environments - environments they have not visited/ experienced or have knowledge of. This can be through increased travelling as tourists and visitors to other towns and cities, through redevelopment of town centres or through cognitive decline, where the familiar becomes unfamiliar. Although there are qualitative differences in the experience of unfamiliarity in relation to time and use of space, between these three contexts there are transferrable elements that are important to be considered when considering the outdoor environment. The spatiality of ageing will be influenced by unfamiliarity of place as a consequence of personal competence, lifestyle or changes in spatial structure.

"Attachment to place" within the gerontological literature is associated with long time periods of exposure to a place and has significantly contributed to how we give meaning to the spaces inhabited and used by older people. Place identity has been described as the individual's incorporation of place into the larger concept of self; a "potpourri of memories, conceptions, interpretations, ideas, and related feelings about specific physical settings, as well as types of settings" (Proshansky et al. 1983: 57). Space is defined here as "general" (Tuan 1974) as opposed to "specific", objective as opposed to subjective or as Agnew (2005: 82) describes "space refers to location somewhere and place to the occupation of that location". Consequently, place is space which has social and emotional meaning and is socially constructed. We also define "place" 
in this study on a macro scale, for example, a city or town, rather than in micro terms of accommodation or home. A further concept introduced here is that of placelessness, where a place conveys no sense of identity, emotion or attachment.

Given increasing globalization and consequent mobility that exposes older people to unfamiliar environments, the concept of placelessness is increasingly relevant. This article reviews the conceptual frameworks underpinning the two broad concepts: first of place attachment that is biological, social, psychological and the concept of familiarity with place; and secondly the experience of unfamiliar place and placelessness which may be experienced for both short and long periods of time, e.g. through experiencing the re-development or regeneration of "home" community or town or city; through travel to new environments through leisure opportunities; through migration to a new country; through change in health, sensory deprivation, and experience of cognitive decline. In other words, through changes of personal competence, lifestyle or spatial structure. The article questions the relevance of such concepts for understanding urban lifestyles in later life.

We explore this issue by drawing on a study (Older People's Use of Unfamiliar Space) to demonstrate that even in an unfamiliar environment older people can develop a sense of place through the aesthetics and usability of the environment as well as through shared memories. It must be stressed that this article primarily aims to illustrate the conceptual framework rather than present empirical results. Although the empirical study was undertaken in the UK the argument can be applied in a global context. Ageing itself is a global phenomenon and spaces of ageing are becoming more fluid and global (Phillipson 2003; Rowles 1983), for example through transnational networks of support by and for older people or through global migration; unfamiliar environments can be found across the globe as cities expand, areas rejuvenated or left to decline and people become increasingly mobile. It is important therefore to look at how older people created meaning in such unfamiliar areas.

Against this background this article looks at 'place attachment in later life' and the concept of familiarity before turning its attention to the varied experiences of 'unfamiliar environments' and 'placelessness'. Empirical data is then presented to examine the question of 'How does an unfamiliar 
International Journal of Ageing and Later Life

environment convey meaning?' before concluding with a wider discussion on the spatiality of ageing.

\section{Place Attachment in Later Life}

The disciplines of environmental psychology, cultural and social geography, which have dominated the theoretical framework underpinning environmental gerontology, can help us understand how place can become both an environment for attachment and detachment.

'Attachment to place' and 'place identity' have a long history in the study of ageing research. They are grounded in two particular theoretical frameworks, both of which explore the interaction between the person and his or her environment. Two most recognised and influential scholars in environmental gerontology, Lawton and Rowles, have a long history of shaping theory, policy and practice (Lawton 1977, 1980, 1985, 2001; Rowles 1978, 1983, 2008, 2012). In Lawton's case the well recognised Person-Environment fit model has had significant influence on housing and in particular institutional design and home modification. Lawton primarily from a quantitative, psychological perspective, and Rowles (1978) from a qualitative and geographical ethnography perspective, have framed our understanding of how people become attached to their close environments. The press-competence model developed by Lawton and Nehemow (1973) states that those with low competence encountering strong environmental press are more likely to have maladaptive behaviour (and attachment) compared with those having high competence encountering weak environmental press where behaviour (and attachment) is likely to be positive (Lawton 1980). Lawton (1980) illustrated that if people cannot use or function every day in their environment (because of physical or psychological barriers for example) then they can be less attached to place. Lawton further developed his original 'environmental docility' hypothesis to include concepts of competence and adaptation into what he called the 'environmental proactivity' hypothesis (Lawton 1985, 1998) where persons could shape their own environment. Emotion and cognition and physical and mental competence have become increasingly important in Lawton's model consequently acknowledging the complexity in the person-environment interaction beyond simply 'environmental 
determinism' for which he was originally criticised (Peace et al. 2006). The Person-Environment Fit concept has been developed further to accommodate changes over time in place (Scheidt \& Norris-Baker 2004) and the integration of the social with the physical environment over time, as well as the development of agency, with older people shaping their own environments (Wahl \& Lang 2004).

Such seminal work has been continued by Rubenstein and Parmerlee (1992), Weissman (2003), Wahl and Lang (2004), Oswald and Wahl (2005), Rowles (1978, 1983, 2008) and Peace and colleagues (2006), developing place attachment in relation to the social environment and emotional and psychological aspects of meaning in the person-environment interaction. The literature is not expansive however on unfamiliarity as a concept.

Rowles $(1978,1983)$ argues that older people's attachment is linked to their construction of personal identity and identifies components of attachment to place: physical insidedness - physical attachment and familiarity with a place; social insidedness - integration into the social fabric of the community and developing a sense of belonging through participation and through nurturing group identification with the neighbourhood, and autobiographical insidedness relating to the personal history of the individual in relation to place. Attachment to place can be built up over a lifetime of experiences (Rowles \& Watkins 2003; Rubenstein \& Parmerlee 1992) and emotional attachment to place can be both temporary and permanent.

Whether 'insidedness' is geographical or social, attachment to place and place identity can rarely be immediately created in a new environment (Tuan 1977) but is experienced through long-term involvement with a location (Morgan 2010). Our view on place may be shaped through our 'landscapes of memories' (Rowles 1983), recollections of childhood places, artefacts, material possessions and past events, and on meaning alongside personality and autobiography. For older migrants in the study by Cuba and Hummon (1993b), it was based on satisfaction with the new dwelling and on its positive contrast with the previous home; in other studies, different patterns of place attachment are associated with the meaning and feeling of place (Massey 1994; Twigger-Ross \& Uzzell 1996). Children have different patterns of place attachment based on activity within a space (Hart 1979; Hay 1998; Moore 1986), or relationships with friends and 
International Journal of Ageing and Later Life

family (Cuba \& Hummon 1993a). Hernández and colleagues (2007) in a study of natives and non-natives found that bonds were established to places where people had lived for considerable periods of time or where they had moved from other places, which had a similar spatial and cultural frame of reference. Belonging to a different city entailed a decrease in the levels of attachment. It is not surprising that we find comfort in familiarity, created through length of residency, social integration within the community, access to services and neighbourhood satisfaction.

Rowles (2008) also talks about "being in place", which evolves over the lifecourse and is a product of our actions. We have processes of 'making' and 'remaking place' and in relocation we transfer our meaning of place in space and time. Any move in later life may be traumatic for those who have never moved before; conversely, others who have moved many times may have refined place-making skills, e.g. in arranging furniture in similar spatial configurations and through psychological preparation and anticipation. Artefacts, he argues, help us create and maintain a history and shape our autobiography. The essence of "being in place" is a tapestry grounded in location and personal history.

From these studies it is evident that time and familiarity are important aspects in place attachment and place identity. All the above rely on attachments building over time suggesting an 'intimate familiarity' with place where functioning within the environment becomes automatic, and where people know how to interact with each other (Burholt 2006). Hay (1998), in taking a lifecourse approach, found that place attachment increased with age, with place attachments formed earlier in life being stronger than those formed later in life. Length of residency is a variable, which is a direct predictor of place attachment in numerous studies (Lewicka 2010) with few notable exceptions (Fleury-Bahi et al. 2008; Harris et al. 1996) that do not find attachment to neighbourhood due to long-term interaction with place.

How long it takes for someone to become attached to place can vary from individual to individual and will depend on how they adapt to change. Golant (2003) talks of a "trajectory of change" analysis depending, not just on the current level of competence of the older person, but the capability of the person in the past and likelihood in the future to influence change. 
There may also be generational and historical effects. Certain generations will have particular memories associated with place, for example, the attractions of the tourist spa towns in England in the early 20th century or the pilgrimages to particular world destinations imbue attachment and belonging for certain generations. Different expressions of attachment with place depend on where people are in their lifecourse. Attachment may also be linked to historical events (such as the 1966 Aberfan disaster which brought a Welsh mining community together in a shared identity in the face of tragedy), which make bonding a strategy for survival. Consequently, attachment to place is not a static concept of spatial ageing, a factor often assumed in ageing in place initiatives; it is dynamic at both individual and societal levels.

Much of the work on place attachment has focused on rural communities (Keating 2008). Features of the rural community, in terms of the aesthetical qualities of the environment or the social embededness often conveyed in the image of the rural setting have been identified as factors linked to attachment (Burholt 2006). Such places may be easily attractable and attachable because of their natural qualities. Chapman and Peace (2008) found that women's sense of identity, particularly in rural Canada, was tied to the land and their desire to age in the natural landscape with family and friends around them: "Distinguishing place from self was difficult" (2008: 31).

However, several studies look at urban attachments (Phillipson et al. 2000) and attachments in deprived urban communities (Smith 2009; Scharf et al. 2003). Fried (2000) suggests that place attachment might be even stronger in deprived neighbourhoods. Place attachment might be greater for people who have few physical, economic and social opportunities other than place around which to focus a sense of belonging. Those with greater resources can seek social gratification elsewhere. In other words if the environment is unsuitable people with resources have agency to detach themselves and move to other environments and become attached elsewhere.

Place attachment has also received attention in policy and practice and in the UK for example, the concept has been a strong component underpinning the policy of "Ageing in Place," often defined as the ability of an older person to age in a stable environment. The focus of policy has 
International Journal of Ageing and Later Life

also been on location, design and built environmental context of ageing in place. This has been reinforced through the UK policy initiatives to future proof design through guidance such as Lifetimes Homes, Lifetime Neighborhoods (DCLG 2008)-a strategy which sets out to plan for appropriate housing and neighbourhoods designed across the lifecourse; Care and Repair schemes (to improve the housing of older people) and the move to develop age-friendly communities.

The theoretical, policy and practice developments around attachment to place demonstrate the complexity of the interaction between person and environment over time. What does this mean for place identity in later life? Peace and colleagues (2006), drawing on the work of Twigger-Ross and Uzzell (1996), conclude that place identity is developed through the "'distinctiveness of place; 'continuity' - places forming a constant reminder of the self; 'self-esteem' - whether places allow people to feel good about themselves and 'self efficacy' - whether the environment is manageable to maintain daily lifestyles" (2006: 159).

A new strategy may be necessary to maintain self identity if adaptive behaviours cannot balance place identity with declining competence (Peace et al. 2006). It is at this point in what Peace and colleagues (2011) describe as "option recognition" that modification to behaviour or environment is sought. All these components again require time and a certain familiarity with the environment.

\section{Unfamiliar Environments}

In developing an understanding of what makes a place, what leads to attachment to place and place identity, it appears that time and associated familiarity are key concepts.

Unfamiliarity is under defined as a concept but has been considered in the sociological literature as synonymous with 'strangeness' (Schutz 1944). It signifies that which is unknown or even incomprehensible in terms of accustomed categories of one's "thinking as usual" (Cohen 1972). The Oxford English dictionary defines unfamiliar as "not known or recognizable," "unusual or uncharacteristic." 


\section{Placelessness}

Relph (1976) describes placelessness as "the casual eradication of distinctive places and the making of standardised landscapes that results from an insensitivity to the significance of place" (preface). Hummon (1992) constructs a typology where people may move from being ambivalent about a place to be considered placeless with little sense of identity, emotion and attachment to an area. Hay (1998) argues that aesthetic connections gained by tourists and travelers, are however superficial and such people exhibit "uncommitted placelessness" as described by Hummon (1992). There has been very little empirical work carried out on the concept of placelessness and the definition as constructed by Relph (1976) has been criticised for being too simplistic and ignoring temporal, social and individual circumstances that shape particular places and people's experiences of them (Seamon \& Sowers 2008). Considering these distinctions we describe placelessness as a lack of "insidedness" and meaning, anomie or simply not knowing a place. Placelessness may be as a result of exclusion or may itself lead to exclusion being made unwelcome or not having the resources to engage in the spatial environment.

Placelessness is also linked to a temporal frame and can be created where people have little time to put down roots as they pass through spaces such as hospitals, care homes, airports and shopping malls (Augé 1992; Miles 2010). Augé (1992) links such mobility to placelessness and consequently placelessness can be linked to unfamiliarity (of the physical and social environment). Unfamiliarity can lead to detachment and placelessness but we know little of the factors that contribute to this and what contributes to the meaning of space and attachment in an unfamiliar environment.

Trends of globalisation, increased travel, multiple living spaces and longevity of the population challenge these underlying concepts and frameworks. Demographics surrounding family life are changing and challenging notions of place attachment. Reconstituted families, increasing single households, caring at a distance, multiple-location living and mobility, mobile and remote technologies and changing levels of cognitive functioning are all challenging "ageing in place" as a concept as well as place attachment as a single location. Social networking has the potential to change our emotional attachment to place, as more remote connections are valued. 
International Journal of Ageing and Later Life

Boldy (2009) argues that "ageing in place" should have a wider definition as to baby boomers location is more important than house or home. Place can also be many places and not about a building or location but even a lifestyle. Different places may have significance at different stages of lifecourse and as such we should consider the effects of dementia and illness on attachment and familiarity with place (Hay 1998).

For these reasons it is timely to relook at the concept of attachment to place, particularly in relation to the underpinning notion of familiarity. Unfamiliarity with place may be an increasing phenomenon challenging our understanding of what makes an age friendly environment.

There are a number of reasons why unfamiliarity is an important concept to study within the context of ageing and the environment:

First, unfamiliarity with one's location occurs when the built environment is new; an experience encountered by increasing numbers of older people as they travel the world as tourists or have to relocate due to necessity or choice in later life. Increasing globalization and technological advance provide more opportunities to travel than ever before. Those who have the capacity and resource to travel will experience unusual and unknown places. It has been argued that "such strangeness to remain enjoyable has to be experienced from the security of some familiar shelter, ameliorated by a touch of familiarity, or even demarcated as unrealstaying on the cruise ship" (Dann 2000: 611). Conversely, older people moving because of care needs or on health grounds - may have a small radius of movement in their new environment making their search for familiar spaces and places difficult.

For some people travelling to unfamiliar places as tourists can be exciting, attractive and alluring; for others travel to an unfamiliar location is threatening and risky; they may be emotionally ambivalent to the locality (Hummon 1992). Cohen (1972) argues that it is the extent to which unfamiliarity attracts or repels individuals depends on the intensity of the exposure to it and the degree of their preparation and experience of similar encounters. For the unprepared, being alone without language can be threatening. If prepared it can be an attractive challenge. Discussion of unfamiliarity in the travel literature has concentrated on how to manage or minimize it (Dann 2000) so as not to lead to culture shock in unfamiliar environments. 
The issues for the traveller are fundamentally different from those who do not move through choice. They are likely to revolve around finding the comfortable areas to enjoy, navigating the street network to find key landmarks and sites or the places they have come to visit. There may not be a biological, social or psychological attachment to place. A degree of unfamiliarity will be acceptable as they wander around unfamiliar sites, knowing that their unfamiliarity will be temporary; their degree of confidence may depend if they are alone or with others. Given the increasing availability of mobile and innovative technologies such as Google Street View, older people are able to prepare for such forays from the comfort of their home.

Second, as urban landscapes change through regeneration or decline, the use of space changes and previously familiar places may become unfamiliar (Phillips 1999). What might have been familiar through growing up in a place with distinctive shops and landmarks may now be unfamiliar as a result of a homogenized Macdonaldization effect, characteristic now of many US and UK towns and cities. Older people may be vulnerable, insecure and powerless within such contexts.

Although older people may stay put the environment around them also changes as environmental fabric decays or in-migrants settle around them, potentially creating unfamiliar environments. What is place attachment at one point in time may become place detachment at a later point. With climate change what was an attractive area to live in can become vulnerable and threatening. What was once a lovely active holiday resort is now a disabling environment where accessibility is difficult and streets are dirty.

The issues for older people here are that familiar cues such as particular buildings, signs and memories are permanently lost through demolition and replacement. Often such changes can be accompanied by the decline of social networks, decreased confidence in walking around the area or loss of familiar cues such as signposts. How older people adapt to such changes will depend on how they have adapted in the past, whether they have moved at all during their lifecourse and what replaces the "familiar" area. Adaptation to change is a constant feature for older people who move house into unfamiliar interior space and have developed strategies and routines over their lifecourse to create meaning in each new setting 
International Journal of Ageing and Later Life

(Rowles et al. 2004). The process of "place making" and personal identity are interlinked, however temporary a place may be.

Third, with changes in cognitive functioning some older people will experience unfamiliarity in their previously recognizable household surroundings (Setterstein 1999). Although considerable work has focused on people with dementia in the institutional environment, less work has concentrated on the home, or more so, on the outdoor built environment (Mitchell \& Burton 2006) where change is a constant factor whether it be at street level or large scale planning. People with dementia can get lost and become disorientated, particularly in unfamiliar environments.

We can learn from research with people with cognitive impairment in relation to unfamiliarity in the home environment. Van Hoof and Kort (2009) in reviewing the literature find the two most important aspects of the indoor environment were lighting and thermal comfort.

Looking at the outdoor environment, Duggan and colleagues (2008) explore the impact of early dementia on outdoor life found that going outdoors regularly added to peoples' quality of life as they were able to exercise and informally meet friends and neighbours. However, the familiarity of the environment was important; changes caused confusion and, as a result, sometimes people with dementia stopped going out altogether. People with dementia tend to avoid unfamiliar environments and tend to move within gradually smaller areas as their cognitive ability decreases.

Small changes to familiar objects and outdoor cues can be significant in making the environment become unfamiliar. The study by Brorsson and colleagues (2011) found that repainted houses, road diversions or familiar objects rearranged in supermarkets made familiar and comfortable areas into unfamiliar and inaccessible public spaces. Maintaining familiarity of activity and place was important to people with AD. This can be made difficult with the use of "everyday technologies, such as self service checkouts, in crowded places with high tempo and noise, and where there were changes in the personal and recognisable landmarks of older people." These changes reduced feelings of accessibility. Older people in the study reported that they "were no longer so fond of what they called "adventures" or of performing unfamiliar activities in unfamiliar spaces. At present they located almost all their activities in a familiar space. This 
meant that the public space that the informants felt was comfortable had gradually become smaller" (Brorsson et al. 2011: 591); a finding replicated in work by Shoval and colleagues (2011).

Good design however is essential for everyone, not only people with cognitive impairments and in familiar and unfamiliar environments. How the design of streets and neighbourhoods can make a difference to older people's well-being and quality of life has been highlighted through a body of research undertaken under the Inclusive Design for Getting Outdoors (IDGO) initiative. The effects of well designed tactile paving, clear "shared space" and the importance of lifelong neighbourhood design have all been highlighted (Newton \& Ormerod 2008; Sugiyama \& Ward Thompson 2007; Thies et al. 2011).

The experience of older people under these three different contexts is different. For example, the traveler could adapt knowing that such unfamiliarity is temporary while for those experiencing environmental change or cognitive decline and have no agency, the unfamiliar environment can be threatening and insecure and a permanent state of unfamiliarity. There are lessons however we can transfer from one situation to the other in how older people convey meaning in later life to unfamiliar settings.

\section{How Does an Unfamiliar Environment Convey Meaning to Older People?}

To explore the question this article draws on findings from the Older People's Use of Unfamiliar Space (OPUS) study. The OPUS study was conducted in two town centres of the UK; one town in South Wales (Swansea) familiar to the 44 participants in the study and one unfamiliar town centre in Eastern England (Colchester). The overall aim of the study was to investigate how older people used and experienced urban town centres that were both familiar and unfamiliar to them. Unfamiliar was defined as environments they had not visited or experienced or had knowledge of.

Forty-four older volunteers, all over 60 (mean age 71) were interviewed to collect both quantitative and qualitative data. Sixty percent (26) of the sample was female with $40 \%$ (18) male. All participants were ambulatory 
International Journal of Ageing and Later Life

with no pre-existing diagnosis of cognitive impairment (average scores for male and female participants using CASI were 96.3 and 97.0, respectively). Thirty-two of the 44 considered themselves to be "always fit and healthy". The group was drawn from primarily middle-class organizations (U3A; Network $50+$ ), which required a high level of participation and this was reflected in that most were well educated and well travelled. Twenty-eight respondents often travelled to towns unfamiliar to them. The majority were native to South Wales and had lived in the Swansea area for considerable lengths of time.

Following a survey covering their demographic background, experiences of travel etc., 2D images and routes in familiar and unfamiliar towns were displayed in a "reality cave" and participants were asked to comment on general impressions and distinctive features, for example the use of signage, confusing and helpful cues, colours, lighting.

A smaller group (10) of Swansea participants in the research was then taken to an unfamiliar town centre. This group, who were self-selecting from the 44, followed the route "for real" with a "walk around town" accompanied by a group of older local residents (10) from Colchester who were familiar with the area and the researchers. The two groups (Swansea visitors and Colchester residents) also met as a focus group following the accompanied walk to discuss their experiences. The Swansea residents also met with spatial planners. Qualitative data were collected through participants recording their experiences in notes (as they walked) and through discussions with the group of local residents and local planners. The quotes below are from both the cave and reality.

This study aimed to explore the environmental factors within a location that enable people "unfamiliar" with it to become attached. We were interested in investigating the physical domain (rather than the social) and two key themes emerged from the data: The aesthetics and the usability of the environment, both contributing to how older people conveyed meaning in an unfamiliar environment.

The aesthetic and emotional components of location and the appropriateness of the environment explored through the OPUS data to illustrate the components of the environment, which could lead to feelings of detachment or placelessness. In relation to the former little research has explored 
the aesthetics of the urban and built environment rather than concentration placed on the aesthetics of the natural physical world.

The aesthetics of the urban environment were very important in establishing people's first impressions of the town, both in the reality cave and more so in the actual environment.

Our data suggests that historic buildings and landmarks appear to be pivotal characteristics or "anchor points" (Couclelis et al. 1987) of the town landscape for making sense of a place. Spaces of greenery interspersed with the built landscape also provided aesthetic appeal:

\begin{abstract}
We are now passing columns with something carved on the top and they would be worth pausing at to look at, and what looks like a very old pub on the right: cycle stands for the cyclists; more pedestrian crossings, plenty of those and plenty of bus stops; hanging baskets and a balustrade, wrought iron; above the shops some very interesting architecture; a bright yellow building which would be a definitely landmark and especially as it is on the corner of Museum Street, which suggests there is something to explore there; and attractive old buildings, the white ones with a bow window above the functional shop fronts. (Virtual cave)
\end{abstract}

The negative images or aesthetics led some people to feel "detached" from the place (not wishing to have association with it in the first instance). Arriving at the train station confronted with boarded up shops, traffic noise, untidy greenery and litter detracted from a positive appreciation of the urban landscape. Similarly, the lack of attractive buildings and historic monuments questioned why they had come to the area:

\footnotetext{
I wasn't particularly impressed by the railway when the train come into the station, looks a bit run down I think. (Real environment)

Very busy road- buses, lorries, many cars: I hope there is something more interesting to see in this town. (Real environment)
}

The aesthetical qualities of place were also considered important to those who were familiar with their environment. Historic buildings were recalled with a memory of the civic pride of yesteryear; individual memories of places and spaces also created meaning through shared emotions.

The second category of statement connected to the physical environment included the accessibility and ease of mobility. This again suggests that familiarity over time is a key issue; people felt it difficult to attach themselves 
International Journal of Ageing and Later Life

to a place within a very short period of time if the condition of the urban fabric, e.g. the state of the pavements and crossing areas, presence of street furniture, litter and rubbish was poor making accessibility difficult. More examples of usability and accessibility were mentioned in the real environment rather than the virtual cave as illustrated below:

There is poor access here and evidence of more stands they don't give the pedestrians much room here, even with the bus stops there, poor waiting areas and obstructions. (Real environment)

For a town centre the pavements are very narrow with a lot of people having to walk out onto the road to get passed; pavements a bit uneven, he's going to be run over, standing in the middle... There are very uneven pavements. (Real environment)

One of the greatest detractions from appreciating the aesthetic qualities of the built environment was the necessity to concentrate on one's mobility. Shared spaces for cars, bikes and pedestrians left many feeling nervous about being in an unknown centre with unwritten rules about priority of way. Similarly, what we have termed "sensory overload" of smells, sight, colour and noise as well as large moving crowds led to detraction from the positives of the urban landscape.

\footnotetext{
Rubbish in the road, trees in the middle of pavements. You've got to be very careful there, oh look at that, oh yes with the uneven surface around there; you can fall down there quite easily... now we've got bollards in the way. I wonder why they're there, but, keep walking, awful lot on this pavement isn't there, a lot of obstructions on that pavement but we're crossing the road. another post is on the road... cars on pavements, they should not be there. (Real environment)
}

Despite the barriers and complexity of the environment to our older visitors many were able to create a sense of meaning in spaces and places that were unfamiliar to them. However in contrast familiar areas (Swansea town shown in the virtual cave to Swansea participants and Colchester residents in speaking of Colchester in the focus group) evoked a sense of emotion and history. Images of the local, familiar area viewed in the reality cave led participants to convey a sense of history behind the scenes describing the former and current usage and history of a building, consequently providing greater detail of the image. In a similar way the 
hidden "unseen" landscape beyond the immediate vision formed part of people's perception of the area. Older people were taking a much wider spatial lens describing the view beyond the scene. When questioned on what landmarks people used in navigating and orientating in a familiar landscape through the series of still images they talked of the "dangers of the street behind," the difficulty of walking down the road because of the bollards or described the ambience of the setting as "a popular leisure area." Thus, even areas that are familiar can potentially have unseen "dangers" behind what appears on view. A well known market was vividly described by all respondents yet only the frontage of the market had been displayed in the cave; similarly as car drivers many people highlighted the dangers of a blind spot or talked about the speed limit on a particular road that could not be seen. People were also knowledgeable of the environment around-the road bridge over the river; the green spaces that were used as "playing fields". In unfamiliar areas the scene was described in terms of the colours of the buildings, distinctive landmarks, detailed layout of the road and features and fixtures along the roadside bollards and fencing. The narratives of unfamiliar areas lacked depth and insight into areas compared to familiar scenes.

Taken together with the above, these findings indicate that the meaning of space is important: cognitive maps are constructed through more than just physical and built environments. Emotional spaces are pertinent for older people. Places and spaces are imbued with memories, histories and identities that enable people to navigate familiar environments. Memories are used as "shortcuts" in giving directions. In looking for toilet facilities, one resident commented:

\footnotetext{
I think sometime that you don't appreciate the knowledge that these older people have got but if you don't make use of it now and another generation you will have lost it. Things that they can recall and if you are re-establishing an area the memories of an older person can sometimes trigger things off. (Focus group with planners)
}

\section{Discussion}

"Ageing in place" and "attachment to place" remain important concepts in relation to later life. The majority of older people want to remain at home, 
International Journal of Ageing and Later Life

many having lived in their home and locality for a number of years and even with the loss of social and civic participation their attachment to an environment remains strong (Bonvalet \& Ogg 2007; Phillipson et al. 2000).

Places age and change as people age-what at one time is a suitable place to age may become inappropriate at a later time. How older people with their associated memories and identities attached to place make sense of new and unfamiliar environments is increasingly important to examine, particularly in light of the increase in cognitive impairment when people have little choice about being in "unfamiliar" environments.

Throughout the article we have stated that the three potential contexts in which unfamiliarity of place may occur can be experienced differently by older people. People who are cognitively impaired, have low personal competence and lose their spatial skills or through relocation or regeneration will experience the unfamiliar environment differently to those who have by choice of lifestyle travelled to unfamiliar places as tourists or visitors. All three have an impact on the spatiality of ageing. For the first and second group seeking familiarity their radius of movement may become much smaller as the familiar may shrink in spatial scale. For the traveler their lifestyle may thrive on unfamiliarity as they experience it as a temporary and a positive choice. However all three groups can make sense of their unfamiliar environment if the aesthetics and usability of the environment is conducive to conveying meaning.

\section{A Sense of Unfamiliar Place}

Is unfamiliarity a relevant concept to understand urban lifestyles in later life? People use environments and take actions, perform behaviours that give them a sense of place, even if there is no emotional attachment to place. Unfamiliarity however does not necessarily mean people do not use spaces or that places are meaningless and emotionless. Unfamiliar urban environments can have meaning (even negative). The key issue to positive aspects of attachment is whether they provide an aesthetically pleasing image and are usable; this based not just on functional ability of an older person in the environment but on their psychological attachment and assessment of the usability of that space.

In relation to the physical fabric of the outdoor environment we know that place attachment is related to features such as the presence of 
aesthetically pleasant buildings, quiet areas and the presence of green areas-all positive predictors of place attachment (Bonaiuto et al. 1999).

This resonates with Lynch's (1960) work on "Images of the City" where he argues that a successful landscape should possess the two desirable urban qualities of imageability (the ability of objects to evoke strong emotions in an observer) and legibility (the organisation of elements of the city that allows them to be seen as a coherent whole). This he argues leads to distinctive areas clearly interconnected in a way that citizens can appreciate (Lynch 1960). Closeness to prominent landmarks in a city, easily defined edges of neighborhood and good quality of housing stock are also important in creating meaning (Gieryn 2000). We also know that people with cognitive impairments continue to use landmarks and signs in their way finding strategies (Brorsson et al. 2011; Sheehan et al. 2006).

Unfamiliarity is not synonymous with meaninglessness or placelessness. Exclusion (from social, spatial and material resources) can lead to detachment and placelessness as older people are unable to participate in particular places and spaces due to barriers in the environment. Unfamiliar areas can have meaning for people in later life if they are aesthetically pleasing and are usable. Practical ways to develop more enabling environments are increasingly important across the lifecourse (Iwarsson \& Ståhl 2003) and are detailed in Phillips (2012). Lessons on how to create enabling environments that are aesthetically more pleasing and usable however can be learnt from disciplines outside of gerontology particularly through occupational therapy. Time-use as a method used in leisure studies may also be fruitful avenue to review older people's use of unfamiliar space (Chatzitheochari \& Arber 2011).

\section{Brief Encounters}

The OPUS data looked at a historic town centre where tourists come with a specific purpose-their attachment is as a tourist or visitor in the town centre; most studies on place attachment have not looked at such centres but have concentrated on the neighbourhood and rural areas looking at function and context and over greater periods of time. An exception to this can be found in the works of Kyle and colleagues (2004) and Williams and Roggenbuck (1989) who looked at more recreational settings similar to that in the OPUS study where place attachment may be more punctuated 
International Journal of Ageing and Later Life

and brief. In both cases a sense of place and community differed between those with long-term familiarity (where place attachment was stronger) and those having more sporadic contact with a location.

However, we have to challenge the notion that place attachment can only be developed through familiarity and long time frames. Lewicka (2005) found that socio-demographic factors were more important in place attachment than length of residence. Place identity (as opposed to place attachment) may take longer. Hernández and colleagues (2007) found that for non-natives attachment to place was a much quicker process than place identity. In examining the literature they also conclude that length of residency in an area is "mediated by others such as the number of relationships within a community, home ownership or otherwise, the presence of incivilities on their property, and even the scope of attachment analysed" (Brown et al. 2003; Giuliani 1991: 311). The OPUS study indicates that older people can develop meaning and a sense of place within a short period of time.

\section{Challenging the Person-Environment Framework}

There is a need to revise our understanding of familiarity with place and how a person's interaction with their environment plays out in later life to accommodate unfamiliarity. The challenge comes from the concentration in many frameworks to understand the person-environment interaction on the basis of familiarity. Unfamiliarity needs to be incorporated as a dimension in environmental press. The research also supports the notion of person-environment-activity as a further dimension.

It is here a focus on "place" can assist. Physical structures may not necessarily be a component of place; we have to understand the concept of place; what activities are important in that place and then consider what form enables those activities to occur. The OPUS study describes what makes a place and conveys meaning and attachment (or not) in a place, which is unfamiliar. Our study does not rest on the notion that as an historic town it will naturally be attractive to older visitors and convey a sense of history and meaning. This has to be created through activity, aesthetics and usability. The individual's perception of the environment is crucial in terms of their actions within an environment. 
If we look at the conceptions and behaviours, which make a place, then we understand how people become attached to place and put meaning into it. "Ageing in place" has traditionally been couched in the environmental determinism framework (if you create a particular place such as a retirement community such activities will result or certain environments will determine certain behaviours or by giving people a sense of ownership and hence security and control in their environment then they will successfully and actively age in place). We need to go further and explore what conveys meaning in an environment for older people, particularly public urban environments. Further research is needed in this area, particularly looking at the strength of attachment over time and other factors in the environment such as the spatial arrangement of social connections and networks.

What we argue is that although place identity and attachment to place are linked to familiarity and length of residence there are other environmental factors at play, such as the aesthetics of place. Older people who display a sense of place through "autobiographical insidedness" (Rowles 1983) and well connected social networks display feelings of security and belonging. However, it is crucial to look at the superficial environmental factors as many people developing cognitive impairment may lose both social connections and a sense of self. Given Lawton's "Person-Environment Fit" then the environment and its aesthetic qualities become of crucial importance.

\section{The Meaning of Place}

The meaning (as well as use) of place may change as people age. Preserving memories of places is important in relation to regeneration of towns and city areas for locals as they "age in place"; creating character and ambience can be difficult in new areas - preserving or recreating meaning can be appropriate in some areas. Older people familiar with the environment can add to the planning process through their collective memories and experiences. For spaces to become places, emotion and meaning has to be embedded in such spaces. This can be created by recording historical facts about an area or collecting stories from local residents. Experience and ambience are less well acknowledged but essential if older people are to be interested and encouraged to visit unfamiliar places as tourists. This expands the work of Rowles and 
International Journal of Ageing and Later Life

colleagues (2004) to the outdoor environment. It is apparent that the "encounter" between older people who were visiting (from Swansea) and local older people (from Colchester) in the OPUS study revealed that despite different cultural backgrounds there was a mutual appreciation of the issues brought into the focus group discussion by both groups. This suggests that listening to the views of local older residents may be helpful in making places less worrisome to older visitors. Memories are applicable in creating meaning in the wider environment, which can be used to sustain independence for those older people "ageing in place". Attachment to place is tied into such collective memories (Burholt 2006). A biographical lifecourse record of a "walk around town" would be useful to help capture key memories and histories of the location. Memory and orientation however are complex issues - some memories will be false or distorted or negative and painful and people will have different points of reference. Older people come with a variety of experiences and knowledge of areas, which planners need to pay attention to if areas are to become attractive, safe and walkable. Such emotional responses and histories can become important cues for older people in navigating an unfamiliar environment. An unfamiliar space can have meaning through such reminisces but these can be negative as well as positive or some aspects such as the physical can be negative while the social and psychological could be positive and may vary on subsequent visits. Developing the meaning of space and place is also a spatial skill, which older people possess, in relation to familiar areas.

Understanding the associations between ageing and the environment consequently takes us to consider concepts of unfamiliarity. However the connection between unfamiliarity and placelessness should not be assumed and as a result we need to consider refining our concept of "Person-Environment Fit" to help understand ageing in the $21^{\text {st }}$ century. Unfamiliarity of place will increasingly be a concept we need to discuss in the context of older people's lifestyles of mobility; the increasing prevalence of dementia within the population and the changing nature of the urban environment. The concept of unfamiliarity is useful to understand urban lifestyles in later life.

Mobile technology and the Internet can however make the unfamiliar more familiar from the comfort of one's home where a tourist can plan on 
how and where to travel in the unfamiliar environment. As the OPUS study showed, such features cannot as yet replicate gradient, noise, smell of particular lighting settings and a combination of all of these at once. New technology can play a part in wayfinding support (FUTURES 2007).

\section{Conclusion}

As stated at the outset, this article is a "think piece" that reviews some of the conceptual aspects of environmental gerontology concerning attachment to place and familiarity in relation to person-environment interaction and considers the implications for meaning and behaviour when places are or become unfamiliar. It challenges our mainstream understanding of the spatiality of ageing - how older people interact with places as they age and develops further theoretical perspectives through the concept of unfamiliarity. The article uses empirical research to briefly demonstrate ways in which unfamiliar places can hold meaning through the aesthetics and usability of place. Additionally, it demonstrates that older people's voices are central to understanding what and how a sense of meaning and attachment can develop. Research has shown that for older people who were familiar with the area, attachment was conveyed through shared memories of events and situations around particular places and buildings. Such a sense of attachment can be conveyed to the unfamiliar traveller helping them to gain an appreciation of the environment and share in such attachment. For the unfamiliar place a sense of meaning can be conveyed through the aesthetics and facilitated through the ease of accessibility. This has implications increasingly for older people with cognitive impairment particularly if we are to develop and shape outdoor environments that are inclusive. We need to look at older people in general as well as older people with dementia to understand what conveys meaning and a sense of attachment when that environment is unfamiliar. This assessment can also be helpful for older people as migrants in a foreign land, travelers across the globe and for people experiencing changes in their landscapes through regeneration. Without a consideration of how meaning is conveyed in the unfamiliar environment there is a danger that the unfamiliar can become placeless and lead to insecurity and detachment as well as link to fear and lack of confidence in travelling. 
International Journal of Ageing and Later Life

\section{Acknowledgements}

The OPUS study was funded by the Research Councils New Dynamics of Ageing Research Programme (NDA) grant number RES-352-25-0003. We also acknowledge other members of the research team - Prof. Nigel Foreman, Dr. Mike Lewis, Edgar Samarasundera, Mark Del Aguila and all the older people who took part in the study.

\section{Corresponding Author}

Judith Phillips, Centre for Innovative Ageing, Swansea University, Singleton Park, Swansea, SA2 8PP, UK. Email: judith.e.phillips@swansea.ac.uk

\section{References}

Agnew, J. (2005). Space: Place. In P. Cloke and R. Johnson (eds.), Spaces of Geographical Thought (pp. 81-96). London: Sage.

Augé, M. (1992). Non-Places: Introduction to an Anthropology of Supermodernity. London: Verso.

Boldy, D. (2009). Ageing in place in the UK: Issues for policy and practice. Paper presented at Conference on Ageing Landscapes, The Australian Association on Gerontology, Freemantle, November.

Bonaiuto, M., Aiello, A., Perugini, M., Bonnes, M. \& Ercolani, A. P. (1999). Multidimensional perception of residential environment quality and neighbourhood attachment in the urban environment. Journal of Environmental Psychology 19: 331-352.

Bonvalet, C. \& Ogg, J. (2007). Ageing in inner cities: The residential dilemmas of the baby boomer generation. International Journal of Ageing and Later Life 2(2): 61-90.

Brorsson, A., Öhman, A., Lundberg, S. \& Nygård, L. (2011). Accessibility in public space as perceived by people with Alzheimer's disease. Dementia 10(4): 587-602.

Brown, B., Perkins, D. \& Brown, G. (2003). Place attachment in a revitalized neighbourhood: Individual and block level analysis. Journal of Environmental Psychology 23: 259-271. 
Burholt, V. (2006). "Adref": Theoretical contexts of attachment to place for mature and older people in rural North Wales. Environment and Planning A 38: 1095-1114.

Chapman, S. \& Peace, S. (2008). Rurality and ageing well: "A long time here." In N. Keating (ed.), Rural ageing: A good place to grow old? (pp. 21-32). Bristol: Policy Press.

Chatzitheochari, S. \& Arber, S. (2011). Identifying the third agers: An analysis of british retirees' leisure pursuits. Social Research Online 16(4): 3.

Cohen, E. (1972). Towards a sociology of international tourism. Social Research 39(1): 164-82.

Couclelis, H., Golledge, R., Gale, N. \& Tobler, W. (1987). Exploring the anchor- point hypothesis of spatial cognition. Journal of Environmental Psychology 7(2): 99-122.

Cuba, L. \& Hummon, D. M. (1993a). A place called home: Identification with dwelling, community and region. The Sociological Quarterly 34: $111-131$.

Cuba, L. J. \& Hummon, D. M. (1993b). Constructing a sense of home: Place affiliation and migration across the life cycle. Sociological Forum 8: 547-570.

Dann, G. (2000). “Unfamiliarity”. In J. Jafari (ed.), Encyclopedia of Tourism (pp. 611). Oxford: Routledge.

Department of Communities and Local Government. (2008). Lifetime Homes Lifetime Neighbourhoods: A National Strategy for Housing in an Ageing Society. London: DCLG.

Duggan, S., Blackman, T., Martyr, A. \& Van Schaik, P. (2008). The impact of early dementia on outdoor life: A 'shrinking world'? Dementia 7(2): 191-204.

Fleury-Bahi, G., Félonneau, M-L. \& Marchand, D. (2008). Processes of place identification and residential satisfaction. Environment and Behavior 40: 669-682.

FUTURES (2007). FUTURES: Navigating the city - supporting the unfamiliar traveller. Research briefing sheet 006, Centre for Transport and Society, Bristol University, UK. Available on http:/ / www.transport.uwe.ac.uk/ (Accessed: December 27, 2011). 
International Journal of Ageing and Later Life

Gieryn, T. F. (2000). A space for place in sociology. Annual Review of Sociology 26: 463-496.

Giuliani, M. V. (1991). Towards an analysis of mental representations of attachment to the home. Journal of Architectural Planning Research 8: 133-146.

Golant, S. M. (2003). Conceptualizing time and space in environmental gerontology: A pair of old issues deserving new thought. The Gerontologist 43(5): 638-648.

Fried, M. (2000). Continuities and discontinuities of place. Journal of Environmental Psychology 20(3): 193-205.

Harris, P., Brown, B. \& Werner, C. (1996). Privacy regulation and place attachment: Predicting attachments to a student family housing faculty. Journal of Environmental Psychology 16(4): 287-301.

Hart, R. (1979). Children's Experience of Place. New York: Irvington.

Hay, R. (1998). Sense of place in developmental context. Journal of Environmental Psychology 18(5): 29.

Hernández, B., Hidalgo, M., Salazar-Laplace, E. \& Hess, S. (2007). Place Attachment and place identity in natives and non-natives. Journal of Environmental Psychology 27: 310-319.

Hummon, D. M. (1992). Community attachment. Local sentiment and sense of place. In I. Altman \& S. M. Low (eds.), Place Attachment (pp. 253-277). New York \& London: Plenum Press.

Iwarsson, S. \& Ståhl, A. (2003). Accessibility, usability and universal design - Positioning and definition of concepts describing person-environment relationships. Disability and Rehabilitation 25(2): 57-66.

Keating, N. (ed.). (2008). Rural Ageing: A Good Place to Grow Old? Bristol: Policy Press.

Kyle, G., Graefe, A., Manning, R. \& Bacon, J. (2003). An examination of the relationship between leisure activity involvement and place attachment among hikers along the Appalachian Trail. Journal of Leisure Research 35: 249-273.

Lawton, M. P. \& Nahemow, L. (1973). Ecology and the ageing process. In C. Eisdorpher \& M. P. Lawton (eds.), Psychology and Adult Development and Aging (pp. 619-674). Washington, DC: American Psychological Association. 
Lawton, M. P (1977). An ecological theory of aging applied to elderly housing. Journal of Aging and Environment 31(1): 8-10.

Lawton, M. P. (1980). Environment and Aging. Belmont, CA: Brookes-Cole.

Lawton, M. P. (1985). The elderly in context: Perspectives from environmental psychology and gerontology. Environment and Behaviour 17(4): 501-519.

Lawton, M. P. (2001). The physical environment of the person with Alzheimer's disease. Ageing and Mental Health 5(1): 556-64.

Lewicka, M. (2010). What makes neighbourhood different from home and city? Effects of place scale on place attachment. Journal of Environmental Psychology 30: 35-51.

Lewicka, M. (2005). Ways to make people active: The role of place attachment, cultural capital, and neighbourhood ties. Journal of Environmental Psychology 25(4): 381-395.

Lynch, K. (1960). The Image of the City. Cambridge, MA: MIT Press.

Massey, D. (1994). Spatial Divisions of Labour: Social Structure and the Geography of Production. London: Methuen.

Miles, S. (2010). Spaces for Consumption. London: Sage.

Mitchell, L. \& Burton, E. (2006). Neighbourhoods for life: Designing dementia-friendly outdoor environments. Quality in Ageing-Policy, Practice and Research 7: 26-33

Moore, R. (1986). Childhoods Domain. London: Croom Helm.

Morgan, P. (2010). Towards a developmental theory of place attachment. Journal of Environmental Psychology 30: 11-22.

Newton, R. A. \& Ormerod, M. G. (2008). Towards lifetime neighbourhoods: Improving footways for older people. International Journal of Neighbourhood Renewal 1(1): 44-56.

Oswald, F. \& Wahl, H-W. (2005). Dimensions on the meaning of home. In G. Rowles \& H. Chaudhary (eds.), Coming Home: International Perspectives on Place, Time and Identity in Old Age (pp. 21-46). New York: Springer.

Peace, S., Holland, C. \& Kellaher, L. (2006). Environment and Identity in Later Life. Maidenhead: Open University Press.

Peace, S., Holland, C. \& Kellaher, L. (2011). “Option recognition” in later life: Variations in ageing in place. Ageing and Society 31(5): 734-757. 
International Journal of Ageing and Later Life

Phillips, J. (2012). Older people's use of unfamiliar space. In G. Rowles \& M. Bernard (eds.), Environmental Gerontology: Making Meaningful Places in Old Age. New York: Springer.

Phillips, J., Walford, N., Foreman, N., Hockey, A. \& Lewis, M. (2009). Older People's Use of Unfamiliar Space. NDA Findings 4. Sheffield: Sheffield University.

Phillipson, C. (2003). Globalisation and the future of ageing: Developing a critical gerontology. Social Research Online 8(4). Available on http://www.socresonline.org.uk/8/4/Phillipson.html (Accessed: February 15, 2012).

Phillipson, C., Bernard, M., Phillips, J. \& Ogg, J. (2001). The Family and Community Life of Older People. London: Routledge.

Proshansky, H., Abbe, F. \& Kaminoff, R. (1983). Place identity: Physical world socialization of the self. Journal of Environmental Psychology 3. 57-83.

Relph, E. (1976). Place \& Placelessness. London: Pion.

Rowles, G., Oswald, F. \& Hunter, E. (2004). Interior living environments in old age. In H.-W. Wahl, R. Scheidt \& P. Windley (eds.), Aging in Context: Socio-Physical Environments (Annual Review of Gerontology and Geriatrics 23) (pp. 167-194) New York: Springer.

Rowles, G. (2008). Place in occupational science: A lifecourse perspective on the role of environmental context in the quest for meaning. Journal of Occupational Science 15(3): 127-135.

Rowles, G. (1983). Geographical dimensions of social support in rural Appalacia. In G. Rowles \& R. Ohta (eds.), Aging and Milieu: Environmental Perspectives on Growing Old (pp. 111-130). New York: Academic Press.

Rowles, G. D. (1978). Prisoners of Space? Exploring the Geographical Experience of Older People (reprint edition 1980, pp. 216). Boulder, CO: Westview Press.

Rowles, G. \& Watkin, J. (2003). History, habit, heart and hearth: On making spaces into places. In K. Schaie, H.-W. Wahl, H. Mollenkopf \& F. Oswald (eds.), Ageing Independently: Living Arrangements and Mobility (pp. 77-96) New York: Springer.

Rubenstein, R. \& Parmerlee, P. (1992). Attachment to place and representations of the lifecourse by the elderly. In I. Altman \& S. Low (eds.), 
Human Behaviour and Environment (12) (pp. 139-163). New York: Plenum Press.

Scharf, T., Phillipson, C. \& Smith, A. (2003). Older people's perceptions of the neighbourhood: Evidence from socially deprived urban areas. Sociological Review Online 8(4). Available on http://www. socresonline.org.uk/8/4/ scharf.html (Accessed: February 15, 2012).

Scheidt, R. \& Norris-Baker, C. (2004). The general ecological model revisited: Evolution, current status and continuing challenges. In H.-W. Wahl, R. Scheidt \& P. G. Windley (eds.), Aging in Context: Sociophysical Environments (Annual Review of Gerontology and Geriatrics 23) (pp. 34-59). New York: Springer.

Schutz, A. (1944). The stranger: An essay in social psychology. American Journal of Sociology 49(6): 499-507.

Seamon, D. \& Sowers, J. (2008). Place and placelessness, Edward Relph. In P. Hubbard, R. Kitchen \& G. Valentine (eds.), Key Texts in Human Geography (pp. 43-51) London: Sage.

Setterstein, R. (1999). Lives in Time and Place: The Problems and Promises of Developmental Sciences. New York: Baywood Publishing.

Sheehan, B., Burton, E. \& Mitchell, L. (2006). Outdoor wayfinding in dementia. Dementia 5(2): 271-281.

Shoval, N., Wahl, H.-W., Austlander, G., Isaccson, M., Oswald, F., Edry, T., Landau, R. \& Heinik, J. (2011). Use of the global positioning system to measure the out of home mobility of older adults with differing cognitive functioning. Ageing and Society 31: 849-869.

Sugiyama, T. \& Ward Thompson, C. (2007). Older people's health, outdoor activity and supportiveness of neighbourhood environments. Landscape and Urban Planning 83: 168-175.

Smith, A. (2009). Ageing in Urban Neighbourhoods: Place Attachment and Social Exclusion. Bristol: Policy Press.

Thies, S. B., Kenney, L. P. J., Howard, D., Nester, C., Ormerod, M., Newton, R., Baker, R., Faruk, M. \& MacLennan, H. (2011). Biomechanics for inclusive urban design: Effects of tactile paving on older adults' gait when crossing the street. Journal of Biomechanics. DOI: 10.1016/ j.jbiomech.2010.12.016.

Tuan, Y.-F. (1974). Space and place: Humanistic perspective. Progress in Human Geography 6: 211-252. 
International Journal of Ageing and Later Life

Tuan, Y.-F. (1977). Space and Place: The Perspective of Experience. Minneapolis: University of Minnesota Press.

Twigger-Ross, C. \& Uzzell, D. L. (1996). Place and identity processes. Journal of Environmental Psychology 16: 139-169.

Van Hoof, J. \& Kort, H. (2009). Supportive living environments. A first concept of a dwelling designed for older adults with dementia. Dementia 8(2): 293-316.

Wahl, H.-W. \& Lang, F. (2004). Aging in context across the adult life course: Integrating physical and social environmental research perspectives. In H.-W. Wahl, R. Scheidt \& P. Windley (eds.), Aging in Context: Socio-Physical Environments (Annual Review of Gerontology and Geriatrics 23) (pp. 1-34). New York: Springer.

Weissman, G. (2003). Creating places for people with dementia: An action research perspective. In K. Schaie, H.-W. Wahl, H. Mollenkopf \& F. Oswald (eds.), Ageing Independently: Living Arrangements and Mobility (pp. 162-173). New York: Springer.

Williams, D. R. \& Roggenbuck, J. W. (1989). Measuring place attachment: Some preliminary results. In L. H. McAvoy \& D. Howard (eds.), Abstracts of the 1989 Leisure Research Symposium (pp. 32). Arlington, VA: National Recreation and Park Association. 